\title{
SYNTHETICALLY POWERED ORTHOTIC SYSTEMS
}

\author{
V. L. Nickel, D. L. Savill, A. Karchak, Jun., and J. R. Allen, * \\ Downey, California, United States of America \\ From the Rancho Los Amigos Hospital, Downey
}

The number of severely paralysed patients requiring long-term treatment and care has steadily increased in the last twenty-five years. After the poliomyelitis epidemics of the 1930's, medical treatment improved sufficiently to preserve life in a much larger number of paralytic victims than before. This led to large numbers of patients with a good expectation of life, but arms too weak for useful activity.

Although new cases of poliomyelitis are now quite rare, the number of patients with severe paralysis continues to increase because of accidents, strokes and other disabling diseases. While our first concern is to relieve the psychological and physical discomfort the patient must endure in his position of dependence, the economic burden of providing long-term care for these patients presents society with a problem of some magnitude. A selected bibliography on this subject is given at the end of this paper.

In the past decade a broad investigation has been done on the development of an apparatus to assist in restoring as much independence as possible to the patient. By providing those totally paralysed with mobility and voluntary hand movements, their physical impairment can be reduced sufficiently to allow self-feeding, independent performance of the lesser vocational tasks, and wheelchair locomotion. The degree of independence provided is, of course, directly proportional to the capability of the orthotic device and to the dexterity of the patient in its control.

\section{FITTING CRITERIA}

The patient's determination should be taken into account before devices are fitted because, unfortunately, a patient without determination will not use externally powered devices, regardless of their value. An excellent method of stimulating a severely paralysed patient's interest is to provide him with an electric wheel chair. Practically every patient who has anatomical stability and is capable of sitting in a chair can operate an electric wheel chair if the controls are modified to suit his individual needs. When the patient has gained mobility his whole world is enlarged, his range of interests increased and his personality improved to an amazing degree.

Restoration of hand function can also be achieved and is applicable to almost every paralysed patient. The externally powered flexor hinge hand splint provides the patient with hand motion that is exceptionally functional and simple to apply. Restoration of arm motion, on the other hand, is somewhat more difficult to accomplish because of the complexity of the movements and the power required to do useful work. Artificial arm movement is best done by the orthosis when the externally powered splinting resembles the anatomical arm in the positions of the rotational joints that move it and in its range of segmental displacement. Because of the multiple combinations of joint movements needed for arm movement, control of the orthosis can be somewhat complicated. Sequential joint control and time lag in the system because of the necessity of conscious operation of the control switches or transducers also lowers the performance of the orthosis.

- Nickel, Medical Director, Rancho Los Amigos Hospital, Downey, California; Savill, Consultant in Orthopaedic Surgery, Royal Infirmary and the Princess Margaret Rose Hospital, Edinburgh, Scotland: Karchak, Research Engineer-Orthotic Department; Allen, Research Engineer-Orthotic Department, Rancho Los Amigos Hospital, Downey, California. 
Externally powered orthotic devices must be individually prescribed and fitted because of the variable involvement in different patients, for whom it is important to find out what will best fulfil his needs. There are certain axioms and rules of thumb that should be used. First the degree of disability of the patient must be observed in order to determine the number, quality and location of available control sites. At this time it should also be decided what functions or anatomical members need assistance. Care must be taken not to fit a patient with too many powered devices. If the patient has any useful residual muscle power, such as grasp or elbow flexion, even though the function be very limited, then artificial power should not be supplied to replace this function.

When a powered device is necessary the simplest appliance and controls that can be operated by the patient should be chosen for reasons of economy, simplicity of attachment and adjustment, and reliability. The orthosis should be as attractive in appearance as possible because the patient may reject ugly equipment.

The type of control chosen for a particular fitting is determined primarily by the residual muscle power available at the physiological control site and by the skill of the patient.

\section{TYPES OF POWERED SYSTEMS}

Two types of powered systems have emerged for upper extremity orthotics: 1) the pneumatic systems, which at first were used almost exclusively; and 2) the more recent electric systems, which have shown many advantages and which are now being used most successfully.

Initially, pneumatic systems had the advantage because of the prosthetic arms which had been developed in Heidelberg, Germany, and which were already utilising carbon dioxide as a source of power; several components of this system had a direct carry-over into the field of orthotics. The application of carbon dioxide to orthotics required chiefly a modification of the actuators to make them compatible with the bracing structures because the entire powered orthosis is external to the involved extremity. Carbon dioxide is a relatively inexpensive gas and is usually available. If it is used in a low pressure system (50 to 90 pounds per square inch) little or no hazard exists even in the hands of a layman.

During this same period electric systems were considered but were not developed because of the weight of electric motors and the size of batteries required to provide adequate power. However, with the introduction of electrically powered wheel chairs, these obstacles were overcome. The two 6-volt automobile batteries used to power the chair are sufficient also to power the orthosis. At first this power source was used to fit electro-pneumatic orthoses to patients too weak to activate the standard pneumatic valve. Micro-switches operating solenoids could be operated by patients having 15 grammes of activation force through a range of motion of an eighth of an inch. Several electro-pneumatic systems were thus successfully fitted to patients who previously could not be helped.

Although this worked well, it was apparent that two sources of energy were being used and that simplification would result if the pneumatic source could be eliminated. An electric arm orthosis was made using permanent magnet direct-current motors which gave adequate power for activities previously provided by the pneumatic orthosis. The all-electric system is now a reality and appears to be more compatible with advanced concepts of refined control systems with electrical outputs derived from myo-electric activity or other bio-electric transducers.

The principal advantages of the electrically powered devices are as follows: 1) They are considerably more reliable and do not often need adjustment and repair. 2) They have better response to control information and are less affected by external effects, such as load change. 3) Their joints are bidirectionally driven and do not depend upon gravity or spring tension for reverse movement. 4) Electric energy is easily available in all parts of the country. 5) The cost of recharging the batteries is cheap.

vol. 47 B, No. 3, AUGUST 1965 
Both the pneumatic and the electrical systems have a number of components. Each system will be described and illustrated in relation to the entire arm orthosis. Almost all systems can be divided into three parts: the energy storage unit, the control and the actuator which converts the stored energy into useful mechanical power.

\section{PNEUMATIC SYSTEMS}

Figure 1 shows a standard carbon dioxide tank with a storage capacity of thirteen ounces. The weight of the empty tank is two pounds. Because the vapour pressure of the carbon

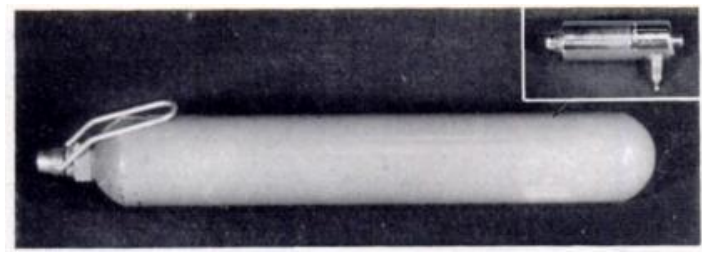

FIG. 1

A standard carbon dioxide tank. Inset, the pressure regulator. dioxide in this tank is approximately 750 pounds per square inch, pressure regulation to the desired range (50 to 90 pounds per square inch) is necessary. The pressure regulator shown in the inset of Figure 1 screws directly into the top of the tank. The handle on the tank operates a valve which opens and closes the tank.

The pneumatic lever valve (Fig. 2) controls the flow of gas from cylinder to actuator.

It is a three-position unidirectional valve shown in the normal position which is off or hold. When the lever is completely depressed gas flows through the valve to the actuator and it is in the fill position. If the lever is depressed only half way. gas flows from the actuator to the atmosphere and it is in the exhaust position. When movement of a limb is to be used for control, the unidirectional valve is of great importance because a hold, fill and exhaust function can be obtained from a single control site, and when few control sites exist the greatest use must be made of them. Five to six ounces of force are required to operate this valve.

Two types of pneumatic actuators have been developed specifically for orthotic purposes. Figure 3 shows the artificial muscle and its component parts. It consists of a tubular rubber bladder covered with helically woven nylon, two end fittings and two crimping ferrules which

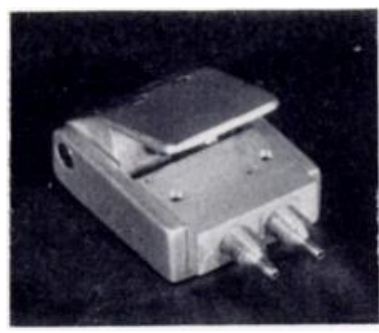

FiG. 2

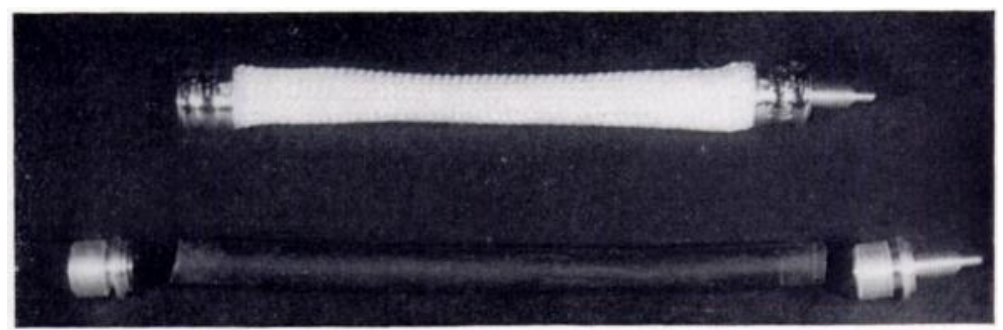

FIG. 3

Figure 2-A pneumatic lever valve. Figure 3-An artificial muscle and its component parts.

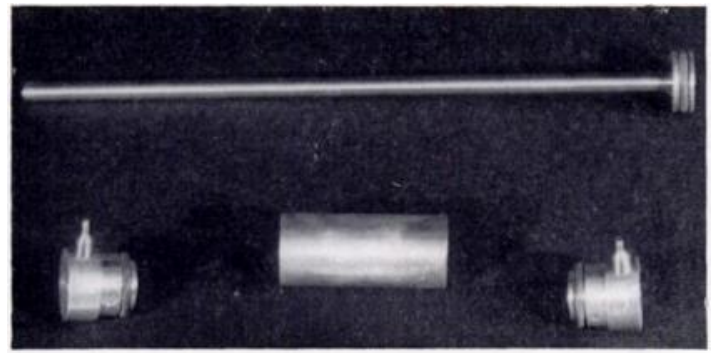

FIG. 4

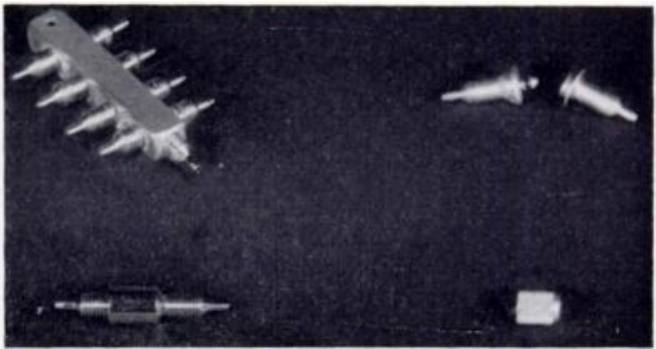

Fig. 5

Figure 4-Parts for piston assembly. Figure 5-Components for assembling a pneumatic system. (See text.) 


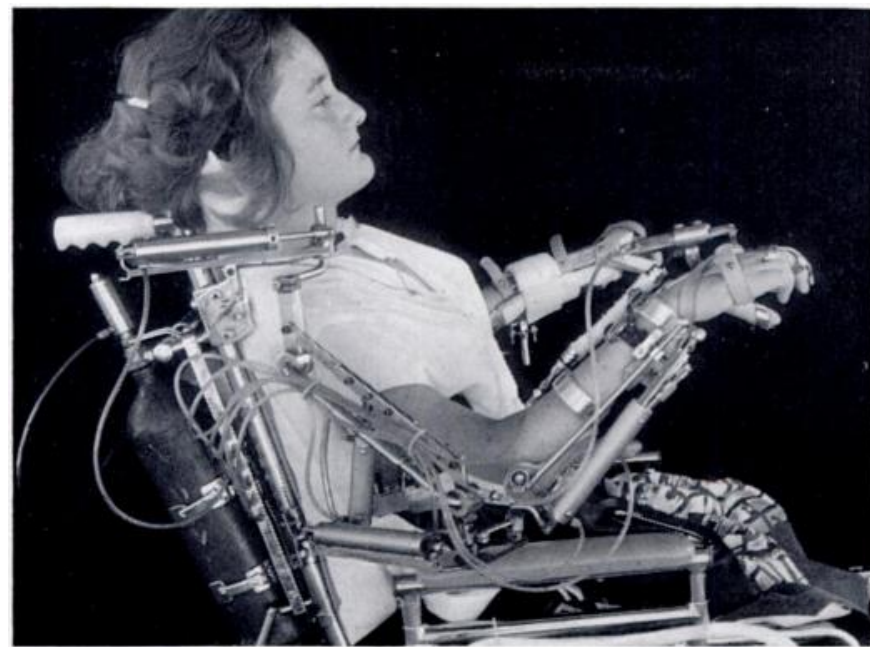

FIG. 6

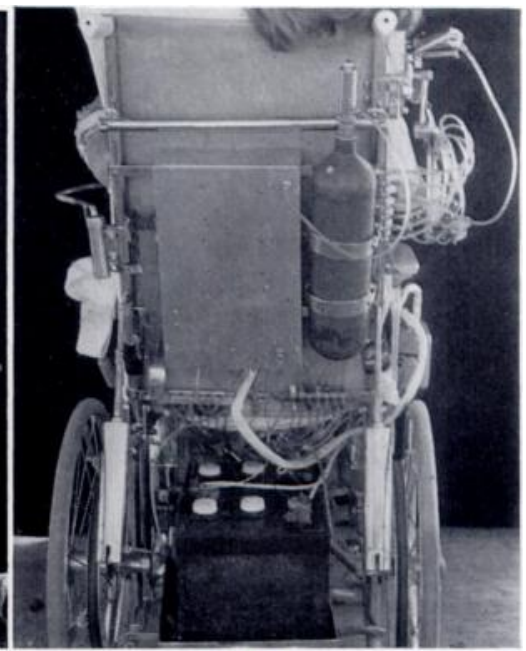

FIG. 7

A pneumatic arm orthosis assembled and in use.

hold the units together. When the bladder is inflated it will contract to about 30 per cent of its original length.

The typical pistons which are used are shown in Figure 4. They are the double-acting type which enables inflation through either end. The end fittings and the pistons are machined and kept in stock; assembly is made as they are needed. When the length of the stroke has been determined for an orthosis the aluminium tubing which acts as the cylinder is cut to the length required and the piston can be assembled in about ten minutes.

Other necessary and useful components which are required when assembling a pneumatic system are shown in Figure 5. Top left is a miniature manifold which permits distribution of gas from a single energy storage bottle to several valves and actuators in the system. Top right is a snap disconnector which enables rapid assembly of any portion of the system. Bottom left is a flow control which restricts or impedes the rate of flow to an actuator, thereby

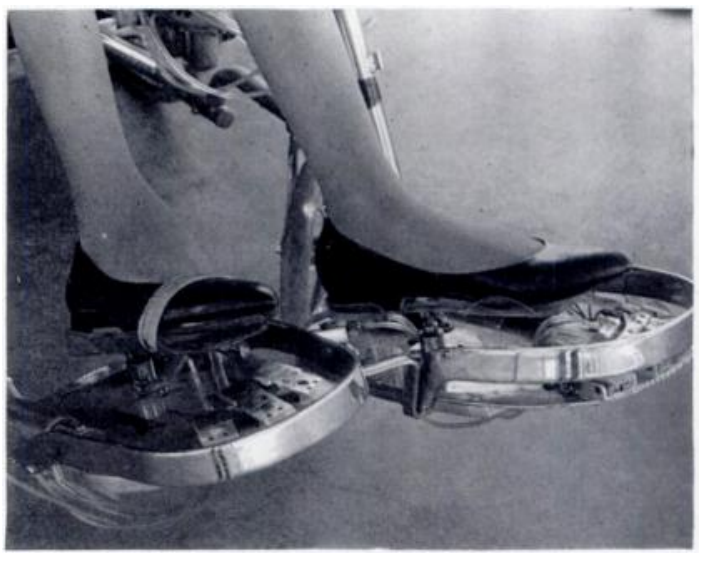

FIG. 8

The foot controls for a pneumatic arm orthosis. slowing down the speed of mechanical movement as desired. Bottom right is a hose ferrule which connects the interconnecting plastic tubing to all the components in the system and holds it securely in place.

The assembly of all the external power sources on an arm orthosis with 7 degrees of freedom is shown in Figures 6 and 7. The lever valves are foot controlled (Fig. 8).

\section{ELECTRO-PNEUMATIC SYSTEMS}

The electro-pneumatic system has already been referred to as a useful method of control for very weak patients who have activation forces of one ounce or less. Micro-switches activate a double bank of solenoids (Fig. 9) which controls the gas flow from the bottle to the actuator.

vol. 47 B, NO. 3, AUGUST 1965 


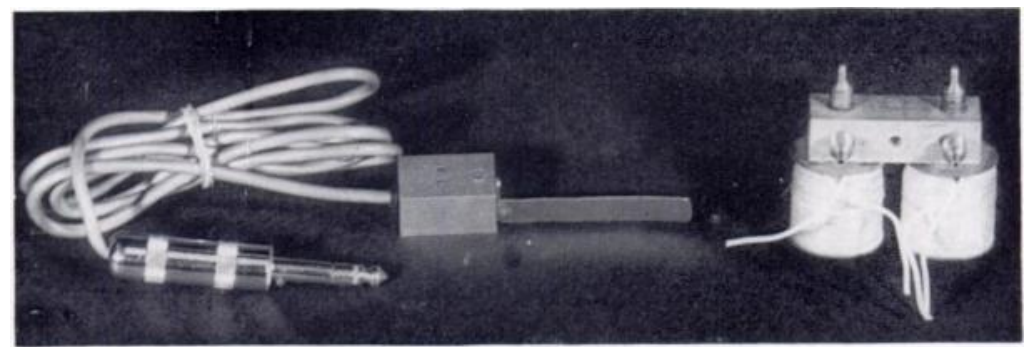

FIG. 9

Electro-pneumatic controls.

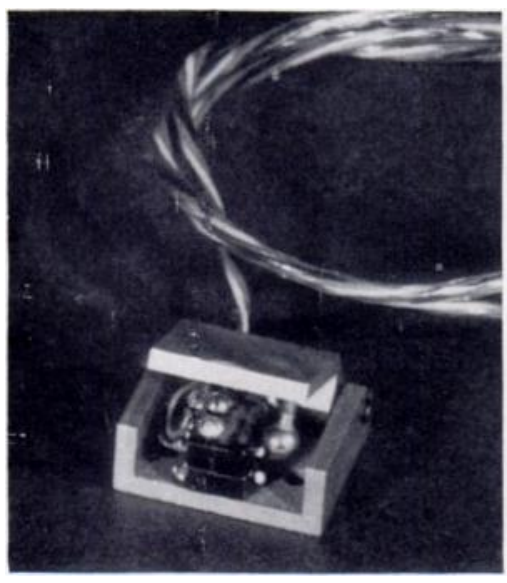

Fig. 10

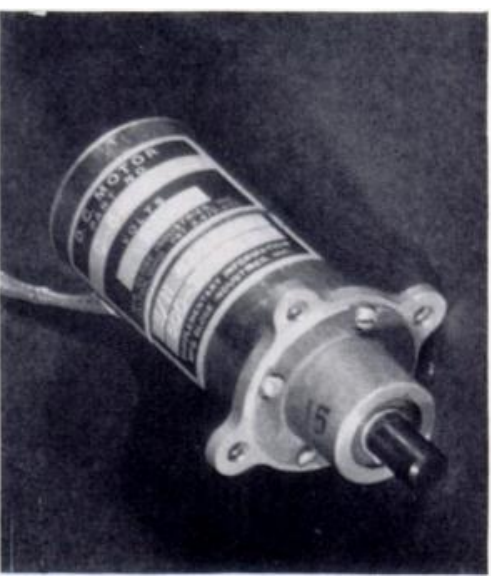

FIG. 11

Figure 10-A lever action electric switch. Figure 11-A typical electric motor unit.

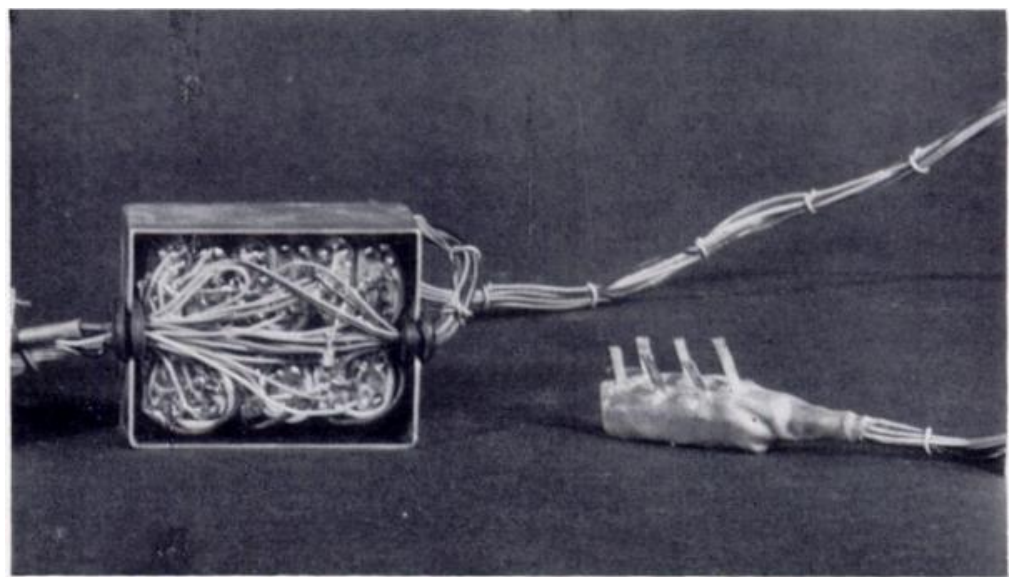

FIG. 12

A bank of seven tongue switches and a miniature relay. 


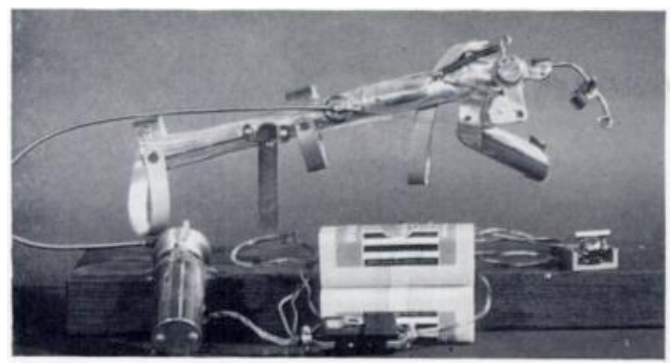

FIG. 13

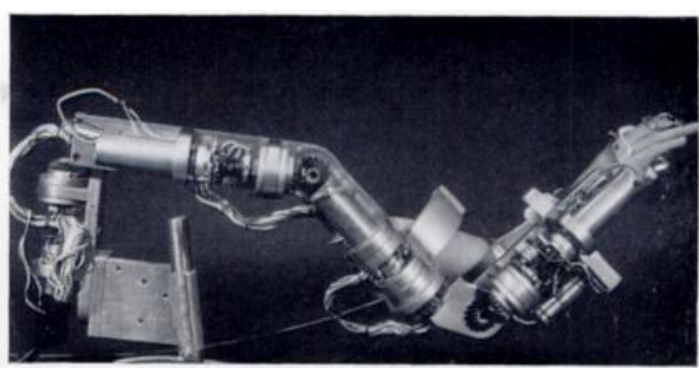

FIG. 14

Figure 13-A simple battery-driven electric prehension system with a flexion hinge hand splint. Figure 14An electric arm orthosis.

\section{ELECTRONIC SYSTEMS}

Electronic systems can be very simple or very complex. Systems, including transducers coupled to amplifiers employing photoelectric cells, capacitance touch plates, strain gauges and impedance devices have been used, but although they have demonstrated that the system functioned, they were far too complicated to control an orthosis or to warrant their additional cost. Simple switching so far has proved very successful for control of coarse movement. The lever action valve shown in Figure 10 operates two micro-switches. Its action is exactly the same as that of the pneumatic valve, and it controls a reversible direct current electric motor such as is shown in Figure 11.

A more compact switching system is illustrated in Figure 12. On the left is a bank of miniature relays which are energised by a bank of seven tongue switches shown on the right. These switches are bidirectional thus providing fourteen control channels. Tongue dexterity in operating these switches is remarkable and is, so far, one of the best methods of control of an orthosis.

Figure 13 illustrates a simple electric system providing prehension for a flexor hinge hand splint and powered by rechargeable nickel cadmium batteries. An electric arm orthosis (Fig. 14) provides 6 degrees of freedom. More recent models of this orthosis have added wrist extension and flexion with a reduction in weight of about 50 per cent. It is anticipated that the new electric arm orthoses will give movements of the arm not only nearer to the physiological normal but also with greater ranges of activity.

\section{CONCLUSIONS}

It is to be expected that the application of external power to replace the lost movement of an arm will be successful if the proper procedures and techniques are used. Success is based on the proper selection of the patient and of the system to be used, as well as on adequate training. In the selection of the patient the psychological aspects are very important. He must be well adjusted to his handicap, well intentioned to the orthosis and have a high gadget tolerance. The orthosis must be carefully chosen to fulfil the needs of the particular patient to the greatest extent possible within the present limitations of production. Finally, training by qualified persons will ensure that the greatest possible use is obtained from the orthosis, starting the patient on a path of activity leading to worthwhile rehabilitation.

\section{SUMMARY}

1. The various methods of powering orthoses are described.

2. The details of control systems are given.

3. The applications of these systems are described.

This work was supported by Grant RD-518 from the Vocational Rehabilitation Administration, Department of Health, Education, and Welfare, Washington, D.C., and Grant RG-7088, National Institute of Health Department of Health, Education, and Welfare, Washington, D.C.

Vol. 47 B, No. 3, AUGUST 1965 


\section{REFERENCES}

Allen, J. R., Karchak, A., Jun., and Nickel, V. L. (1962): Design and Application of External Power and Control Orthotic Devices. Mechanical Engineering, 84, 52.

Engen, T. J. (1963): Development Toward a Controllable Orthotic System for Restoring Useful Arm and Hand Actions. Orthopedic and Prosthetic Appliance Journal, 17, 184.

Geddes, L. A., Moore, A. G., Spencer, W. A., and Hoff, H. E. (1959): Electropneumatic Control of the McKibben Synthetic Muscle. Orthopedic and Prosthetic Appliance Journal, 13, 33.

Geddes, L. A., Hoff, H. E., and Spencer, W. A. (1962): Control Systems for Artificial Muscles. Transactions of the Instrument Society of America, Vol. 1, No. 1, pp. 127-132.

Juvinall, R. C., and Smith, E. M. (1961): Analysis of Design Bases for Upper-Extremity Orthoses. Technical Report No. 1, University of Michigan Medical School.

Kobrinski, A. E., Voskoboinikova, L. M., Ioffe, D. M., Polyan, E. P., Popov, B. P., Slavutski, Ya. L., Sysin, A. Ya., and YaKobson, Ya. S. (1961): Problems of Bioelectric Control. Transactions of the First International Congress on Automatic Controls, Vol. 2, pp. 619-623. London: Butterworths.

LeoNard, F. (1961): A Review of Upper-Extremity Research and Possible Direction of Future Research. The Application of External Power in Prosthetics and Orthotics. National Academy of Sciences Publication, Washington, No. 874, pp. 7-18.

Lyman, J. (1961): Problems of Control and Sensory Feedback. The Application of External Power in Prosthetics and Orthotics. National Academy of Sciences Publication, Washington, No. 874, pp. 22-26.

Marquardt, E., and Haefner, O. (1957): Technical Adequacy and Practical Application of Heidelberg Pneumatic Prosthesis. New York: International Society for the Welfare of Cripples.

Myoelectric Servo Control (1963): Technical Documentary Report No. ASD-TDR-63-70. Bionics Branch, Wright-Patterson Air Force Base, Ohio.

Nickel, V. L., Perry, J., and Garrett, A. L. (1963): Development of Useful Function in the Severely Paralyzed Hand. Journal of Bone and Joint Surgery, 45-A, 933.

Reswick, J. B. (1961): Synthetic Muscle Motor Development. Report No. EDC 4-61-1. Case Institute of Technology, Cleveland, Ohio.

Reswick, J. B., Mergler, H. W., Ko, W. H., Taft, C. K., Bruell, J. H., Corell, R. W., Thomas, D. H., Griggs, K. M., and Gawlowicz, D. J. (1962): Conscious Control of Programmed Motions in Orthotics and Prosthetics. Report No. EDC 4-62-2. Case Institute of Technology, Cleveland, Ohio.

Schulte, H. J., Jun., Adamski, D. F., and Pearson, J. R. (1961): Characteristics of the Braided Fluid Actuator. Technical Report No. 5. University of Michigan Medical School.

Scotr, R. N. (1963): Control Systems for Humans is Goal of New Brunswick Group. Canadian Controls and Instrumentation, pp. 35-36.

Scotr, R. N., and Thompson, G. B. (1963): Orthotic Systems Research. Report 63.5, University of New Brunswick.

Snelson, R., and ConRY, J. (1958): Recent Advancements in Functional Arm Bracing Correlated with Orthopedic Surgery, for the Severely Paralyzed Upper Extremity. Orthopedic and Prosthetic Appliance Journal, 12, 41.

Snelson, R., Karchak, A., Jun., and Nickel, V. L. (1961): Application of External Power in Upper Extremity Orthotics. Orthopedic and Prosthetic Appliance Journal, 15, 345.

Weltman, G., Groth, H., and Lyman, J. (1962): A Myoelectric System for Training Functional Dissociation of Muscles. Archives of Physical Medicine and Rehabilitation, 43, 534.

Wilson, A. B. (1963): Prosthetic and Orthotic Research in the United States. Rehabilitation Literature, Vol. 24, No. 4, pp. $98-107$. 